Disponível em

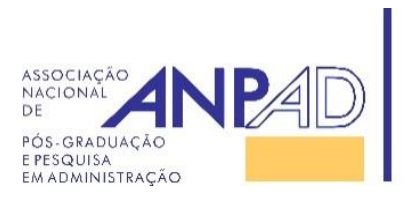

http://www.anpad.org.br/rac

RAC, Rio de Janeiro, v. 22, n. 2, art. 5, pp. 249-270, março/abril, 2018,

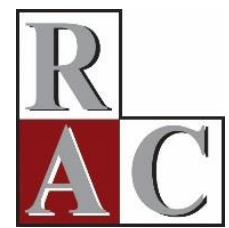

\title{
Influência da Cultura Organizacional Mediada pelo Assédio Moral na Satisfação no Trabalho
}

The Influence of Organizational Culture Mediated by Moral Harassment on Job Satisfaction

Lindomar Pinto da Silva ${ }^{1}$ Miguel Angel Rivera Castro ${ }^{1}$ Marcos Gilberto Dos-Santos ${ }^{2}$

Universidade Salvador, Programa de Pós-graduação em Administração, Salvador, BA, Brasil ${ }^{1}$ Universidade Federal da Bahia, Núcleo de Pós-graduação em Administração, Salvador, BA, Brasil ${ }^{2}$ 


\title{
Resumo
}

Este artigo investigou a relação entre cultura organizacional, a partir de Cameron e Quinn (2006), assédio moral, na perspectiva de Leymann (1990, 1996), e satisfação, a partir da abordagem de Spector (2006), além do efeito mediador do assédio moral entre cultura e satisfação no trabalho, que é a lacuna que este trabalho procura preencher. Os dados foram coletados de trabalhadores de empresas das cidades de Salvador e Feira de Santana, na Bahia, entre os meses de agosto e dezembro de 2016. Obtiveram-se 912 questionários respondidos, analisados por meio de modelagem de equações estruturais. Os principais resultados indicam: (a) as culturas clã e adhocrática são preditoras do assédio moral negativamente, e a cultura mercado influencia-o positivamente, (b) o assédio moral como mediador entre cultura e satisfação possui efeitos significativos em todos os tipos culturais. A principal contribuição é a identificação do efeito do assédio moral na relação entre cultura organizacional e satisfação. Do ponto de vista gerencial, sugere-se que ações visando à satisfação devam considerar culturas que minimizem o assédio moral, além da atenção especial para este fenômeno, já que ele é capaz de minimizar os efeitos positivos da cultura sobre a satisfação.

Palavras-chave: cultura organizacional; assédio moral; satisfação; mediação.

\begin{abstract}
This article investigated the relationship between organizational culture, based on Cameron and Quinn (2006), moral harassment in the view of Leymann $(1990,1996)$ and satisfaction, from the approach by Spector (2006), as well as the influence moral harassment has in mediating the relationship between organizational culture and job satisfaction, which is the gap that this work seeks to fill. Data were collected among workers from different segments in companies from the cities of Salvador and Feira de Santana, Bahia, between August and December 2016. Nine hundred and twelve questionnaires were collected, which were analyzed through structural equation modeling. The main results indicate: (a) clan and adhocratic cultures are negative predictors of moral harassment, and market culture shows to influence it positively; (b) moral harassment as a mediator between culture and satisfaction has significant effects on all cultural types. The main contribution is the identification of the effect of moral harassment on the relationship between organizational culture and satisfaction. From the managerial point of view, it is suggested that actions aimed at satisfaction should consider cultures that minimize moral harassment, in addition to the special attention given to this phenomenon, since it is able to minimize the positive effects culture has upon satisfaction.
\end{abstract}

Key words: organizational culture; harassment; satisfaction; mediation. 


\section{Introdução}

Discussões sobre assédio moral têm sido ampliadas em todo o mundo, em função do aumento da quantidade de casos que têm sido denunciados, e isso mostra que se trata de um problema que precisa ser enfrentado de forma mais eficaz, para evitar as devidas consequências, que são danosas não somente para o indivíduo, mas também para a empresa, para a família da vítima e para a sociedade (C. A. Guimarães, Cançado, \& Lima, 2016; L. A. M. Guimarães \& Rimoli, 2006; Leymann, 1990, 1996; M. Rodrigues \& Freitas, 2014; Nunes \& Tolfo, 2013; Salin, Tenhiälä, Roberge, \& Berdahl, 2014; Suarez, 2002). Incluem-se entre as consequências para o indivíduo: estigmatização e privação dos seus direitos, adoecimentos, aposentadorias precoces, suicídio e dificuldade de manter-se no trabalho e encontrar emprego (Leymann, 1990, 1996).

No que se refere à empresa, as consequências mais comuns são queda de produtividade, absenteísmo, rotatividade, perda de qualidade, redução da capacidade de atrair e reter talentos e perdas financeiras pelos erros cometidos pelos empregados assediados, além de desmotivação e insatisfação (A. L. Guimarães et al., 2016; Divincova \& Sivakova, 2014; Leymann, 1990, 1996; M. Rodrigues \& Freitas, 2014). A redução da satisfação do trabalhador tende a afetar os níveis de produtividade, já que há uma relação significativa e positiva entre satisfação e outros elementos do contexto organizacional, como é o caso do comprometimento e efetividade do trabalhador (Fu, 2014).

Há uma diversidade de indicações de causas para o aparecimento e ocorrência do assédio moral nas organizações. Esses motivos podem ser agrupados em fatores internos ou externos, vinculados às características dos indivíduos agressores ou da vítima. Fatores associados à competitividade dos mercados, que pressionam os atores organizacionais por resultados cada vez maiores e cada vez mais em menor tempo, também estão entre estas causas (Freitas, Heloani, \& Barreto, 2008; Hirigoyen, 2014). Por isso, Nunes e Tolfo (2013) afirmam que se trata de um fenômeno caracterizado por multicausalidade que envolve aspectos psicológicos, interpessoais, organizacionais e ambientais. Entre esses fatores, destaca-se a cultura organizacional (Hennekam \& Bennett, 2017; Terzioglu, Temel, \& Uslu Sahan, 2016).

A cultura define as formas como os indivíduos interagem dentro daquele contexto organizacional, indicando os comportamentos adequados e aceitos pelos respectivos membros (Strese, Adams, Flatten, \& Brettel, 2016). Assim, a cultura pode ter um papel relevante no surgimento e manutenção do assédio moral e da satisfação, posto que ela indica aos membros da organização o padrão de comportamento em relação ao assédio moral (Hennekam \& Bennett, 2017; Terzioglu et al., 2016). É por isso que se tem identificado a cultura organizacional como elemento importante em relação ao assédio moral e satisfação no trabalho (C. A. Guimarães et al., 2016; Hauff, Richter, \& Tressin, 2015; L. A. M. Guimarães \& Rimoli, 2006; M. Rodrigues \& Freitas, 2014; Peltokorpi \& Froese, 2014; Vasconcelos, 2015).

Assim, a primeira contribuição deste estudo é identificar as relações estabelecidas entre tipos de cultura organizacional e assédio moral, além de discutir o efeito mediador do assédio moral sobre a relação entre tipos de cultura organizacional e satisfação no trabalho. Apesar da existência de estudos em que se relacionam cultura e satisfação, tais estudos não consideraram como esta relação pode ser afetada pela presença do assédio moral no contexto organizacional. Além disso, nos trabalhos citados, a metodologia utilizada foi basicamente qualitativa, e os aspectos culturais apenas apareciam como um dos fatores do contexto. Neste estudo, entretanto, a cultura ganha relevância ao se tornar a variável de interesse, além de se utilizar uma amostra com participantes de várias organizações e segmentos e de se empregar abordagem quantitativa por meio de equações estruturais. Para os gestores, identificar os tipos culturais mais propensos à ocorrência do assédio moral pode ajudá-los em processos de gestão, de modo a se evitarem aqueles que potencializam essa prática. Além disso, amplia-se o conhecimento sobre o efeito negativo do assédio sobre a satisfação, mesmo em contextos culturais potencialmente favoráveis à satisfação no trabalho, uma vez que o assédio pode limitar a influência positiva de tipos culturais sobre a satisfação no trabalho. Assim, este estudo se associa à compreensão de Campos e Rueda (2016), que 
sugerem que as pesquisas sobre assédio moral ainda não esgotaram a necessidade de novas investigações.

Dessa forma, o objetivo geral é investigar a influência do assédio moral sobre a relação entre a cultura organizacional e a satisfação no trabalho. Para atender a este objetivo, adotamos uma abordagem quantitativa com aplicação de questionário e análise dos dados feita com uso de análise fatorial confirmatória e modelagem de equações estruturais, tendo o assédio moral papel de mediação da relação. Este artigo está estruturado da seguinte forma: inicia-se com esta introdução, seguida do referencial teórico, onde são discutidos os conceitos de assédio moral, satisfação no trabalho e cultura organizacional. Após isso, é apresentada a metodologia da pesquisa, para, então, se apresentarem os dados e resultados seguidos da referida discussão e das considerações finais.

\section{Assédio Moral}

O assédio moral tem uma diversidade de definições, especialmente em função do contexto cultural do país no qual ele é definido (L. A. M. Guimarães \& Rimoli, 2006; Suarez, 2002). Entretanto, pode-se perceber que, apesar da diversidade de definições, há uma convergência sobre o que se entende por assédio moral. Leymann (1990) define o assédio moral como "uma comunicação hostil e antiética que é dirigida de uma maneira sistemática por uma pessoa ou um grupo de pessoas em direção a um indivíduo" (p. 120). O próprio Leymann (1996) amplia o conceito e destaca que o trabalhador, "devido ao assédio moral, é colocado em uma posição de desamparo e indefeso, sendo mantido por meio de atividades de assédio continuadas" (p. 168). Assim, o assédio moral se configura como ação sobre o indivíduo que, pela natureza de hostilidade, tem a capacidade de produzir efeitos prejudiciais (Parzefall \& Salin, 2010).

Ainda no campo das definições, Suarez (2002) considera assédio moral "um comportamento indesejado que tem como objetivo e consequência atentar contra a dignidade da pessoa e criar um contexto intimidatório, hostil, degradante, humilhante ou ofensivo" (p. 285). Por sua vez, Hirigoyen (2014) entende o assédio moral como "toda e qualquer conduta abusiva por comportamentos, palavras, atos, gestos, escritos que possam trazer dano à personalidade, à dignidade ou à integridade física ou psíquica de uma pessoa" (p. 65). Nessas definições, o comportamento de assédio moral, pelo conjunto de práticas que em si mesmas são ofensivas, revela quão perverso é este processo, dado que a diversidade de ações acaba por inibir ou reduzir as chances de defesa do indivíduo, o que tende a fragilizá-lo, levando-o ao sofrimento, que em alguns casos pode ter como maior consequência o suicídio (Leymann, 1990, 1996).

Leymann (1996) acrescenta que o assédio ocorre, quase sempre, diariamente e por períodos de muitos meses, e que, além de colocar a pessoa em uma posição indefesa, pode, potencialmente, levá-la à expulsão da empresa. Freitas, Heloani e Barreto (2008) reforçam o aspecto da periodicidade das práticas, ao afirmarem que é uma "conduta abusiva, intencional, frequente e repetida que diminui, humilha, constrange e desqualifica, e visa a demolir psiquicamente o indivíduo" (p. 37). Nesse sentido, Freitas (2001) já considerava que a prática do assédio moral leva à fragilização e neutralização do indivíduo no ambiente de trabalho. Leymann (1996) chama este evento de terror psicológico, tanto pelas práticas engendradas pelo assediador quanto pelas consequências desse ato (Parzefall \& Salin, 2010).

Por outro lado, Leymann $(1990,1996)$ considera que o assédio moral pode ser percebido mediante mecanismos utilizados pelo assediador, que operam de formas diferentes no ambiente de trabalho. A partir do trabalho de Leymann (1990, 1996), L. A. M. Guimarães e Rimoli (2006) agruparam esses mecanismos em três categorias: "um grupo de ações que se desenvolvem quanto à comunicação com a pessoa atacada, outro que tenta denegrir-lhe a reputação, e um grupo que tende a denegrir a dignidade profissional" (p. 185). Além disso, esses mesmos autores consideraram a necessidade da inclusão de mais um grupo de mecanismos, proposto por Suarez (2002), denominado de manipulação das contrapartidas laborais. 
A manipulação da comunicação, conforme Leymann (1996), caracteriza-se pela negativa do agressor em dar ao padecedor qualquer possibilidade de se comunicar no ambiente do trabalho. Tentase silenciá-lo, assim como lhe são negadas informações relativas ao contexto do trabalho. Essa manipulação, segundo L. A. M. Guimarães e Rimoli (2006), pode envolver a restrição da comunicação em relação ao contexto de trabalho, o que dificulta não só a compreensão do trabalho a ser realizado, bem como o cumprimento de prazos e os devidos padrões de qualidade. Ocorre também quando são feitas críticas e ameaças publicamente, ou quando o assediador evita qualquer tipo de comunicação com o assediado, e se lhe atinge, assim, o equilíbrio psicológico e emocional (Hirigoyen, 2014).

L. A. M. Guimarães e Rimoli (2006) acrescentam a este processo a "comunicação hostil e o negar cumprimento" (p. 185), postura que Leymann (1996, p. 170) considera como "você é silenciado". Neste aspecto, Hirigoyen (2014, p. 76) vai dizer que "não se lhe diz nada que possa permitir-lhe compreender o que acontece". Em todas essas práticas, a vítima tende a ser isolada, não somente do assediador, mas também dos demais membros do grupo que tendem a afastar-se dela, por medo de represálias, especialmente se o assediador estiver em posição hierárquica superior a ela e aos demais colegas de trabalho.

Na manipulação da reputação do padecente, o assediador realiza comentários com o objetivo de ridicularizar publicamente características físicas do assediado, assim como as suas ideias e convicções, num processo que gera abalo a quem sofre este tipo de agressão (L. A. M. Guimarães \& Rimoli, 2006). Leymann (1996) afirma que fofocas sobre ele são veiculadas, outros membros do grupo o ridicularizam e costumam criticar-lhe, inclusive, a herança étnica, a maneira de andar e falar. Nesse aspecto, L. A. M. Guimarães e Rimoli (2006) consideram que críticas ao profissionalismo da vítima também são patrocinadas como forma de atribuir-lhe os problemas pelos quais ela está passando.

Na manipulação do trabalho da pessoa assediada, o assediador não lhe repassa tarefa alguma de trabalho. Dá-lhe apenas afazeres tidos como monótonos ou desnecessários num claro processo de desvalorização e desmotivação. Além disso, conforme L. A. M. Guimarães e Rimoli (2006), procedese ao aumento da carga de trabalho, de modo a impedir que o indivíduo consiga realizá-lo e tenha, como consequência, $\mathrm{o}$ ataque à própria reputação. Ainda é possível que o agressor atribua à vítima solicitações contraditórias, cuja realização será dificultada. Ainda neste aspecto, Hirigoyen (2014) considera outro fator perverso desse processo que afeta, inclusive, os seus colegas, que é "a negação de trabalho, ainda que esses colegas estejam sobrecarregados" (p. 79).

A manipulação das contrapartidas laborais ocorre quando o assediado se encontra em estado de discriminação, em relação ao salário que lhe é pago, em comparação com outros colegas, em relação aos demais direitos trabalhistas, ou quando há uma discriminação em relação à forma de tratamento (L. A. M. Guimarães \& Rimoli, 2006; Suarez, 2002). Pode haver, ainda, jornadas de trabalho diferenciadas e horas extras, porém, sem as contrapartidas financeiras, ou de outro tipo. O contrário também é verificado quando os indivíduos desempenham atividades semelhantes, mas o assediado recebe recompensas menores do que as dos demais colegas de trabalho.

\section{Cultura Organizacional}

A cultura organizacional, através de seus valores e crenças, representa expectativas normativas sociais que informam como os membros de uma organização devem comportar-se (Hartnell, Ou, \& Kinicki, 2011). Isso está de acordo com a concepção de Schein (2004), que, ao mencionar os valores como um dos níveis culturais, considera-os elementos que orientam o comportamento dos indivíduos dentro da organização.

Apesar de uma diversidade de abordagens sobre cultura, este trabalho utilizou a abordagem de Cameron e Quinn (2006). Para Cameron e Quinn (2006, p. 17), "a cultura reflete o que é valorizado, os estilos de liderança dominantes, a linguagem e os símbolos, os procedimentos e rotinas, e as definições 
de sucesso que fazem uma organização única". A avaliação e identificação das características culturais de uma organização, na perspectiva desses autores, fazem-se pelo Instrumento de Avaliação da Cultura Organizacional (OCAI - sigla em inglês). O OCAI se baseia no Modelo de Valores Competitivos (Competing Values Framework [CVF]) que, no ambiente organizacional, serve para identificar "estágios de desenvolvimento do ciclo de vida, a qualidade organizacional, as teorias de eficácia, papéis de liderança e papéis de gestores de recursos humanos e habilidades de gestão" (Cameron \& Quinn, 2006, p. 31).

No OCAI, as dimensões características dominantes, liderança organizacional, gestão de empregados, liga da organização, ênfase estratégica e critérios de sucesso são a base para a avaliação da cultura de uma organização. A partir destas dimensões, os autores destacam a formação dos quatro quadrantes que originam o CVF. Cada quadrante reúne um grupo de indicadores de eficácia organizacional, e têm-se como parâmetros a flexibilidade, a estabilidade e os focos interno e externo (Braga, Ferraz, \& Lima, 2014; Fernandes, Lemos, Hoffmann, \& Feuerchutte, 2015). Da associação entre essas premissas, nascem os tipos culturais Hierarquia, Mercado, Clã e Adhocracia (Cameron \& Quinn, 2006; Hartnell et al., 2011).

A cultura hierárquica se caracteriza pela priorização da estabilidade e controle com foco no ambiente interno e integração. Nela, percebem-se "linhas claras de autoridade, regras de tomada de decisões padronizadas" (Cameron \& Quinn, 2006, p. 37). A crença subjacente na cultura hierárquica é que a eficiência resulta do controle que este tipo de cultura consegue desenvolver. Nessa cultura, segundo Hartnell, Ou e Kinicki (2011), os empregados se realizam quando seus papéis são claramente definidos. Comunicação precisa, rotinização, formalização e consistência são valores que estão presentes (Cameron \& Quinn, 2006). Por consequência disso, a organização tende a ser eficiente (Denison \& Spreitzer, 1991; Hartnell et al., 2011; Strese et al., 2016).

A cultura mercado se caracteriza pelo foco no ambiente externo. Predominam a competitividade, a produtividade, os objetivos organizacionais, a busca por rentabilidade, os resultados financeiros e a superação de metas (Cameron \& Quinn, 2006). O foco no alcance de resultados aumenta a competitividade, o que implica maior produtividade (Cameron \& Quinn, 2006; Hartnell et al., 2011). Segundo Hartnell et al. (2011), a crença nesse tipo cultural é que metas claras e recompensas motivam os empregados para a competitividade, de modo a alcançarem as metas necessárias desejadas.

A cultura clã se caracteriza pela flexibilidade, pelo foco no ambiente interno e pela integração, além de adotar valores e objetivos compartilhados, coesão entre os membros da organização, participação, senso de pertencimento, desenvolvimento de pessoas, trabalho em equipe, programa de envolvimento dos funcionários e compromisso corporativo para funcionários (Cameron \& Quinn, 2006). Para Hartnell et al. (2011), a suposição subjacente à cultura clã é que o sentimento de pertencimento do empregado produz mais comprometimento e satisfação com a organização. Assim, o sucesso organizacional depende da própria capacidade de se formar um grupo de trabalho que esteja envolvido com a organização. Por isso, os critérios de efetividade são baseados na satisfação e comprometimento dos funcionários (Hartnell et al., 2011; Strese et al., 2016).

A cultura adhocrática ou inovadora se caracteriza pela priorização da flexibilidade e foco no ambiente externo, fomento do empreendedorismo, criatividade, pioneirismo, foco na criação de uma visão de futuro, ênfase na individualidade, na assunção de riscos, e todos têm grande envolvimento com a produção, com os clientes, com a pesquisa e com o desenvolvimento (Cameron \& Quinn, 2006). Para Hartnell et al. (2011), nesse tipo de cultura, as mudanças podem resultar em novos negócios, de modo que se inclui ainda a produção de novos recursos dos quais a organização dependa para o próprio sucesso. Por isso, cultivar uma visão de futuro leva os membros da organização a serem inovadores e assumirem riscos, já que o critério de sucesso nessa cultura é a inovação (Hartnell et al., 2011; Strese et al., 2016).

Destaca-se que o modelo de Cameron e Quinn (2006) foi utilizado, por entendermos que ele consegue "fornecer um diagnóstico de aspectos importantes do perfil de cultura da organização" (p. 23), além de permitir se analisarem as relações entre as tipologias culturais e outras dimensões do contexto 
organizacional. Além disso, esse instrumento tem já comprovadas tanto a confiabilidade quanto a validade de conteúdo (Hartnell et al., 2011).

\section{Satisfação com o Trabalho}

A satisfação no trabalho pode ser considerada outra variável importante no contexto organizacional. A compreensão dos seus antecedentes e consequentes pode contribuir para se entenderem outros fenômenos dentro da organização, se inferirmos que a satisfação está associada a índices melhores de efetividade dos trabalhadores (Hauff et al., 2015). A satisfação, especialmente no que se refere aos antecedentes, é resultante da percepção do indivíduo sobre seu trabalho, envolvendo os aspectos afetivos que ele considera adequados ou não (Andrade, Costa, Estivalete, \& Lengler, 2017; Locke, 1976; Martins \& Santos, 2006). Dessa percepção, o indivíduo estará ou não satisfeito.

Siqueira (2008) afirma que a satisfação está relacionada ao vínculo afetivo entre a pessoa e o próprio trabalho, no que tange às experiências agradáveis no ambiente em que essa pessoa trabalha. De outra forma, a satisfação, segundo Sanchez-Sellero, Sánchez-Sellero, Cruz-González e Sánchez- Sellero (2014), resulta da comparação entre o trabalho realizado pelo indivíduo em seu dia a dia e sua expectativa em relação a esse trabalho. À medida que o trabalho realizado se aproxima de sua expectativa, o indivíduo se sente satisfeito. Entretanto, para Tamayo (2001) e Warr (2007), a satisfação envolve uma diversidade de fatores, por isso, multifatorial, presentes no ambiente da organização, relacionados à remuneração, carreira, relação com colegas e superiores, clima organizacional, autonomia e conteúdo do trabalho, segurança em relação aos perigos durante o trabalho, posição alcançada pelo trabalho realizado, justiça percebida pelo indivíduo, clareza sobre as expectativas da empresa em relação ao trabalho do empregado, e demandas geradas externamente, como o conflito entre família e trabalho, etc. Por isso, a satisfação no trabalho é considerada um constructo influenciado por uma variedade de dimensões no trabalho (A. L. Rodrigues, Barriquello, \& Morin, 2016; Bigliardi, Dormio, Galati, \& Schiuma, 2012; Sanchez-Sellero, Sánchez-Sellero, Cruz-González, \& SánchezSellero, 2014; Siqueira, 2008).

Spector (1985) entende que a satisfação no trabalho é a "representação de um agrupamento de sentimentos avaliativos sobre o trabalho; uma variável de atitude que reflete como uma pessoa se sente com relação ao trabalho de forma geral e em seus vários aspectos" (p. 695). A avaliação da satisfação no trabalho foi feita por Spector (1985) a partir do Job Satisfaction Survey (JSS), que permitiu se avaliarem as percepções dos trabalhadores em relação às dimensões da satisfação presentes no ambiente de trabalho.

Decorrente da definição de Spector (1985), bem como dos itens da JSS, a satisfação poderá ser mensurada pelo modo global ou por facetas, uma vez que a JSS é composta por nove facetas distribuídas em 36 itens (Oliveira \& Costa, 2016; Spector, 1985). Essa compreensão se alinha à compreensão de Tett e Meyer (1993), que consideram a satisfação como sendo compreendida por ser a ligação afetiva do indivíduo com o trabalho visto ou em sua totalidade (satisfação global), ou com respeito a aspectos particulares (satisfação por facetas). Hauff, Richter e Tressin (2015), por sua vez, declaram que a satisfação é influenciada por várias características do ambiente de trabalho. Entretanto, em qualquer que seja a forma de se compreender a satisfação, percebe-se certa variação tanto na compreensão quanto nas formas de se medi-la. Roman, Sefano, Andrade e Zampier (2012), por sua vez, a partir do trabalho de Spector (2006), categorizaram as nove facetas de satisfação em três grupos denominados de recompensas, relacionamento e natureza do trabalho. Dentro desses grupos, esses autores distribuíram as nove facetas de Spector (2006), que assim ficaram classificadas: (a) Recompensas: salário, oportunidades de promoção e benefícios; (b) Relacionamento: supervisão, companheiros de trabalho e condições de trabalho; (c) Natureza do trabalho: natureza do trabalho, comunicação e segurança.

A partir da classificação de Roman et al. (2012), de cada categoria foi escolhida uma faceta: de recompensas, utilizou-se a oportunidade de promoção; de relacionamento, a supervisão; e de natureza 
do trabalho, natureza do trabalho. No que se refere à oportunidade de promoção, Spector (2006) sugere se incorporar a satisfação com promoções recebidas e a forma como a organização estabelece as promoções, com inclusão do tempo entre as mesmas. Por sua vez, a faceta supervisão diz respeito à forma como os relacionamentos ocorrem entre empregados e superiores, bem como em relação às competências do superior e o quanto o empregado percebe interesse desse superior pelo próprio trabalho. Por fim, a natureza do trabalho foca a satisfação do indivíduo com as atividades que realiza na empresa, envolvendo, ainda, o conteúdo destas atividades. À medida que tais atividades estão de acordo com as próprias expectativas, o indivíduo tende a estar satisfeito nesta dimensão (Sanchez-Sellero et al., 2014).

\section{Hipóteses}

Os tipos culturais e suas respectivas características têm efeitos diferentes sobre a satisfação (C. A. Guimarães et al., 2016; Divincova \& Sivakova, 2014). Espera-se que em organizações com perfil cultural nos tipos clã e adhocrática, os índices de satisfação sejam maiores, já que as características destas culturas (Cameron \& Quinn, 2006) estão entre os elementos que favorecem a satisfação. Por outro lado, as características das culturas hierárquica e de mercado (Cameron \& Quinn, 2006) podem favorecer a redução da satisfação, uma vez que podem piorar o clima organizacional e afetar a satisfação dos trabalhadores (Siqueira, 2008; Tamayo, 2001; Warr, 2007). Assim, propomos as seguintes hipóteses:

H1a: a cultura clã afeta positivamente a satisfação no trabalho;

H1b: a cultura adhocrática afeta positivamente a satisfação no trabalho;

H1c: a cultura de mercado afeta negativamente a satisfação no trabalho;

H1d: a cultura hierárquica afeta negativamente a satisfação no trabalho.

M. Rodrigues e Freitas (2014), C. A. Guimarães, Cançado e Lima (2016), Vasconcelos (2015) e Lima, Barbosa, Mendes e Patta (2014) consideram a cultura organizacional como um fator de favorecimento ou inibidor das práticas de assédio moral. Assim, os tipos culturais podem ser favoráveis à ocorrência do assédio moral ou não (Hennekam \& Bennett, 2017; Terzioglu et al., 2016). Perfis de cultura clã e adhocrática, por suas características (Cameron \& Quinn, 2006), tenderiam a não favorecer a ocorrência do assédio moral, enquanto culturas de mercado e hierárquica tenderiam a favorecerem a própria ocorrência. Nesse sentido, propomos as seguintes hipóteses:

H2a: a cultura clã afeta negativamente o assédio moral no trabalho;

H2b: a cultura adhocrática afeta negativamente o assédio moral no trabalho;

H2c: a cultura de mercado afeta positivamente o assédio moral no trabalho;

H2d: a cultura hierárquica afeta positivamente o assédio moral no trabalho.

Ao se considerarem os efeitos danosos patrocinados pelo assédio moral, espera-se que os indivíduos vítimas do assédio moral reduzam a própria satisfação no trabalho, já que o assédio afeta aspectos importantes da relação do trabalho e que se associam com a satisfação no trabalho, a exemplo da relação com colegas e superiores, clima organizacional e expectativas profissionais (Andrade et al., 2017; Divincova \& Sivakova, 2014; Siqueira, 2008; Tamayo, 2001). Sendo assim, propomos a hipótese H3:

H3: O assédio moral afeta negativamente a satisfação no trabalho.

A partir do que já foi proposto, espera-se que a satisfação no trabalho seja influenciada tanto diretamente pela cultura organizacional, conforme descrito por M. Rodrigues e Freitas (2014), C. A. 
Guimarães et al. (2016), Vasconcelos (2015) e Lima et al. (2014), quanto indiretamente, ou mediada pela presença do assédio moral, posto que este afeta também a satisfação, como descrito por Terzioglu, Temel e Uslu Sahan (2016) e Hennekam e Bennett (2017). Assim, este trabalho assume que, mesmo na presença de perfis culturais que não favorecem a ocorrência do assédio moral, como é o caso das culturas clã e adhocrática, a ocorrência do assédio moral reduz a capacidade de estas culturas favorecerem a satisfação no trabalho. Por outro lado, organizações com perfis de cultura de mercado e hierárquica, quando diante do assédio moral, terão ainda mais reduzida a satisfação dos trabalhadores. Dessa forma, propõe-se a seguinte hipótese:

H4: como mediador entre cultura e satisfação, o assédio moral tem efeito negativo, reduzindo os níveis de satisfação em todos os tipos de cultura.

\section{Metodologia}

O presente trabalho adota uma abordagem quantitativa, descritiva e exploratória com questionários on-line aplicados a trabalhadores das cidades de Feira de Santana e Salvador, no estado da Bahia, pois essas são as duas maiores cidades deste estado e reúnem a maioria das empresas públicas e privadas, o que favorece a ampliação da amostra e diversidade de organizações. O questionário foi aplicado de duas maneiras: virtualmente, por intermédio de e-mails e redes sociais - neste caso, foi também solicitado aos respondentes que indicassem outros indivíduos que preenchessem os prérequisitos de estarem empregados e residirem em uma das duas cidades; e presencialmente, pelos próprios pesquisadores em empresas e faculdades das duas cidades envolvidas. A aplicação dos questionários ocorreu entre os meses de agosto e dezembro de 2016. O questionário possuía perguntas destinadas à caracterização da amostra, como cidade da empresa, faixa etária, gênero, faixa de renda, estado civil, escolaridade, tempo na empresa, segmento da empresa e número de funcionários da empresa. Por fim, o tempo médio para responder ao questionário era de 20 minutos. E ainda, ampliar a diversidade da amostra se constituiu o maior desafio, haja vista que acessar as empresas sempre se apresenta limitador, e foi esta, pois, a principal dificuldade para a coleta de dados, especialmente pela resistência de alguns prepostos de empresas que relutaram em participar da pesquisa.

A amostra, não probabilística e acessada por conveniência, é composta por 912 empregados, sendo $58 \%$ do gênero feminino, e $60 \%$ com idade entre 25 e 45 anos. $49 \%$ dos respondentes têm graduação completa, e $28 \%$ têm escolaridade em nível de especialização, ou maior. Em relação ao número de funcionários das organizações, $33,5 \%$ dos respondentes são provenientes de organizações que possuem entre 1 e 30 empregados, 16,5\% entre 31 e 100 empregados, e 50\%, de organização com mais de 100 empregados. Entre os ramos de atuação mais presentes, destacam-se o setor de serviço, com $25 \%$ de participação, seguido do setor industrial, com $22 \%$, de comércio, com $15 \%$, e de educação, com $13 \%$ dos respondentes.

33,5\% dos respondentes são provenientes de organizações que possuem entre 1 e 30 empregados, $16,5 \%$ entre 31 e 100 empregados, e $50 \%$

Além de questões de identificação, o questionário é composto por três escalas para se mensurarem cultura organizacional, satisfação e assédio moral. Em todas as relações aqui apresentadas, o assédio moral é considerado uma variável latente de segunda ordem com suas quatro dimensões: manipulação da comunicação com a vítima (CV), manipulação da reputação da vítima (RV), manipulação do trabalho da vítima (TV), manipulação das contrapartidas laborais (CL). A mensuração do assédio moral foi realizada com 24 itens oriundos da escala proposta e validada por Leymann (1996). A escolha da abordagem de Leymann $(1990,1996)$ deveu-se, inicialmente, ao fato de existirem já categorias (dimensões) ou grupos de ações de comportamentos associados ao assédio moral, o que permitiu se investigarem relações entre essas categorias e as tipologias de cultura organizacional, bem como as facetas da satisfação a partir das análises de regressão. O instrumento utilizado foi a Leymann Inventory of Psychological Terrorization (LIPT), instrumento já devidamente validado pelo autor e amplamente 
utilizado (L. A. M. Guimarães \& Rimoli, 2006; Rueda, Baptista, \& Cardoso, 2015). Optou-se pela redução da quantidade de itens da escala, para não tornar este estudo inviável pela quantidade de itens a serem respondidos pelos entrevistados. Nesse caso, foram retirados os itens que podiam ser representados por outros em uma das dimensões de manipulação ou que tendem a ser menos intensos, dado que podem ser mais facilmente perceptíveis, como a violência física e o assédio sexual, o que poderia facilitar as ações de defesa por parte da vítima em ações judiciais, por exemplo. Este procedimento também foi utilizado por Rueda, Baptista e Cardoso (2015).

A satisfação no trabalho está com as três dimensões representadas em segunda ordem por um único constructo aqui denominado Satisfação (SAT), e foi medida a partir da escala desenvolvida por Spector (2006) nas dimensões de relacionamento (SRL), recompensa (SRC) e natureza do trabalho (SNT), sendo que se totalizaram 12 itens. A cultura organizacional foi mensurada por meio da escala de Cameron e Quinn (2006), com as quatro tipologias de cultura - clã (COC), adhocracia (COA), hierarquia $(\mathrm{COH})$ e mercado $(\mathrm{COM})$ - com 24 itens (questões) identificadores de uma maior ou menor presença dessas características.

Optou-se, neste estudo, pela escala normativa do OCAI, em lugar da ipsativa, uma vez que o interesse desta pesquisa se centrou em compreender perfis de culturas atuais na percepção dos respondentes, sem a necessidade de se investigar a cultura ideal, conforme proposto na escala ipsativa de Cameron e Quinn (2006). Além disso, conforme esses autores, a dependência entre as respostas na escala ipsativa, em cada questão, dificulta testes estatísticos comumente utilizados, como também sugerem Welter e Capitão (2007), que destacam que, na escala normativa, é possível a realização de comparação interpessoal e de comparação intrapessoal, bem como se favorecem outras técnicas estatísticas, como análise fatorial, que é o caso deste estudo.

A verificação das relações apresentadas foi realizada com o uso de modelagem de equações estruturais (MEE), que é útil na avaliação de modelos empíricos nos quais os constructos analisados são variáveis latentes não mensuráveis diretamente e nos quais se especifica mais de uma variável dependente, estando as variáveis independentes correlacionadas (Hair, Black, Babin, Anderson, \& Tatham, 2009). Assim, o conjunto de equações para o modelo proposto é descrito como:

$$
\begin{aligned}
& S A T \sim \beta_{0}+a \times C O C+b \times C O A+c \times C O M+d \times C O H+i \times A S M+\varepsilon \\
& A S M \sim \beta_{0}+e \times C O C+f \times C O A+g \times C O M+h \times C O H+\varepsilon
\end{aligned}
$$

onde o $\beta_{0}$ representa o intercepto da regressão, os coeficientes $a, b, c$ e $d$ representam os estimadores dos tipos de cultura para satisfação, os coeficientes $e, f, g$ e $h$ representam os estimadores dos tipos de cultura para o assédio moral, e o coeficiente i representa o estimador de assédio moral para explicar satisfação no trabalho, seguindo-se do erro associado ao modelo $(\varepsilon)$.

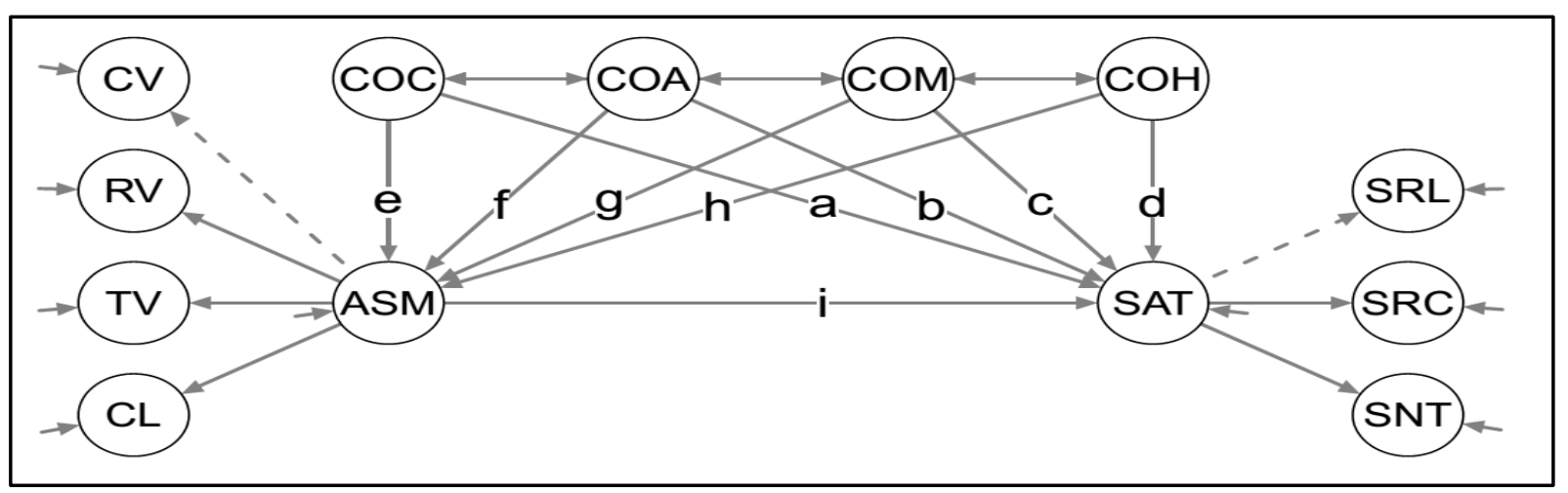

Figura 1. Modelo de Análise da Relação entre Cultura Organizacional e Satisfação no Trabalho Mediada pelo Assédio Moral

Fonte: Elaborada pelos autores. 
O efeito de mediação do assédio moral na relação entre cultura e satisfação será verificado pelo efeito indireto $e \times i$ para COC mediada por ASM, $f \times i$ para COA mediada por ASM, $g \times i$ para COM mediada por ASM, e, por fim, $h \times i$ para $\mathrm{COH}$ mediada por ASM. Particularmente, interessa verificar as diferenças entre o efeito direto da cultura na satisfação e o efeito indireto dessa relação mediada pelo assédio moral (Vieira, 2009).

As etapas para o uso da MEE incluem a análise fatorial confirmatória (AFC) dos construtos envolvidos, seguida da especificação das relações entre os construtos - modelo estrutural, ambas avaliadas por índices de ajustamento que verificam a qualidade da modelagem. Os principais índices utilizados são a estatística $\chi^{2}$ para ajuste do modelo, que apresenta valores mais baixos para os melhores ajustes, além dos graus de liberdade (g.l.) do modelo, sendo que a relação $\chi^{2} / g . l$. deve ser preferencialmente $<5$. Os valores de CFI e TLI devem ser superiores a 0,9 , e os índices de erros RMSEA e SRMR devem ser menores que 0,08 para os melhores modelos (Hair et al., 2009). Os dados foram analisados com o software estatístico R, versão 3.1.1, e foi usado o pacote Latent variable analysis (Lavaan), versão 0.5-20 (Rosseel, 2012).

\section{Tratamento dos dados}

Entre os 912 respondentes, foram identificados e utilizados 864 questionários completos. Os dados não apresentaram normalidade, fato compensado pela amostra com n superior a 300 e uso de estimador de máxima verossimilhança capaz de gerar estimadores robustos à violação de normalidade em amostras grandes (Marôco, 2010; Olsson, Foss, Troye, \& Howell, 2000). A presença de outliers foi investigada pelo critério $D^{2} / g . l .<4$, sendo $D$ a distância de Mahalanobis, e g.l. os graus de liberdade indicados pelo número de variáveis envolvidas (Hair et al., 2009), não tendo sido encontrados outliers na amostra utilizada. A multicolinearidade foi testada com o variance inflation fator (VIF), e todos os valores ficaram dentro dos parâmetros de aceitação (VIF $<5$ ).

Como etapa inicial da modelagem de equações estruturais, procedeu-se à análise fatorial confirmatória (AFC) dos construtos presentes na pesquisa: cultura organizacional em primeira ordem para cada uma das tipologias clã, adhocracia, hierarquia e mercado; satisfação em segunda ordem, e assédio moral no trabalho também em segunda ordem. Para a AFC de Cultura, inicialmente foi especificado um modelo com os itens associados aos tipos de cultura, conforme estabelecido por Cameron e Quinn (2006), o que gerou uma estatística $\chi^{2}=1.113,88$ com 246 g.1., CFI = 0,91, TLI = 0,89 , indicando-se a necessidade de reespecificação do modelo. A opção adotada aqui foi a exclusão dos itens com baixa representação no fator latente, com o $\mathrm{R}^{2}<20 \%$ (Hooper, Coughlan, \& Mullen, 2008). Dois itens se enquadraram nesse critério, $\mathrm{COC} 2$ com $\mathrm{R}^{2}=18 \%$ e COM 1 com $\mathrm{R}^{2}=16 \%$. O modelo reespecificado, conforme a Figura 2, apresentou todos os índices dentro dos parâmetros de aceitação: $\chi^{2}$ $=935,59$ com 203 g.l. que resultou 4,60 do parâmetro $\chi^{2} / \mathrm{g} .1 ., \mathrm{CFI}=0,92, \mathrm{TLI}=0,91, \mathrm{RMSEA}=0,064$ e $\mathrm{SRMR}=0,057$. 


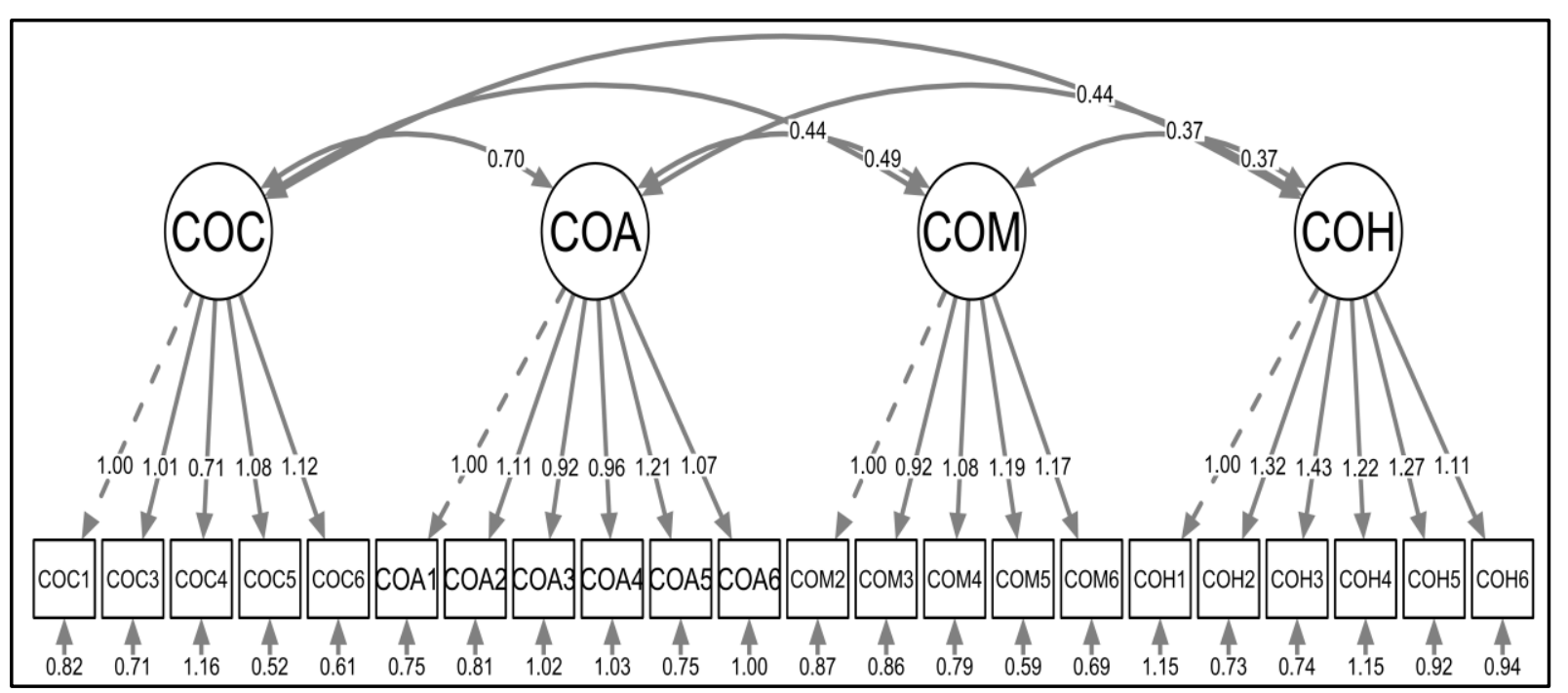

Figura 2. Análise Fatorial Confirmatória em Primeira Ordem de Cultura Organizacional Fonte: Elaborada pelos autores.

A AFC de satisfação no trabalho (SAT) foi conduzida com o modelo em segunda ordem, com as variáveis latentes de primeira ordem SRL, SRC e SNT sendo representadas pela variável latente SAT. Inicialmente, foram invertidos os itens SRL1, SRL4, SRC2 e SNT4, pois apresentavam correlações negativas com os demais itens dos fatores latentes aos quais pertencem. O modelo inicial apresentou $\chi^{2}$ $=661,12$ com 51 g.l., cujo resultado foi 12,96 do parâmetro $\chi^{2} / \mathrm{g} .1$. , CFI $=0,85$, TLI $=0,80$, RMSEA = 0,117 e SRMR $=0,087$. Esses valores indicam que o modelo requer ajustes, e a opção aqui adotada foi a exclusão dos itens com baixa representação na variável latente cujo $\mathrm{R}^{2}<20 \%$ (Hooper et al., 2008). Os itens SRL4 (14\%), SRC2 (17\%) e SNT4 (17\%) se enquadraram nesse critério e foram excluídos.

A Figura 3 mostra o modelo reespecificado, cujos parâmetros são: $\chi^{2}=165,31$ com 24 g.l., resultando-se 6,87 do parâmetro $\chi^{2} /$ g.l., $\mathrm{CFI}=0,96, \mathrm{TLI}=0,93, \mathrm{RMSEA}=0,082$ e SRMR $=0,050 . \mathrm{O}$ resultado indica um ajuste aceitável para SAT. Por fim, foi realizada a AFC de assédio moral no trabalho, representado em segunda ordem por ASM.

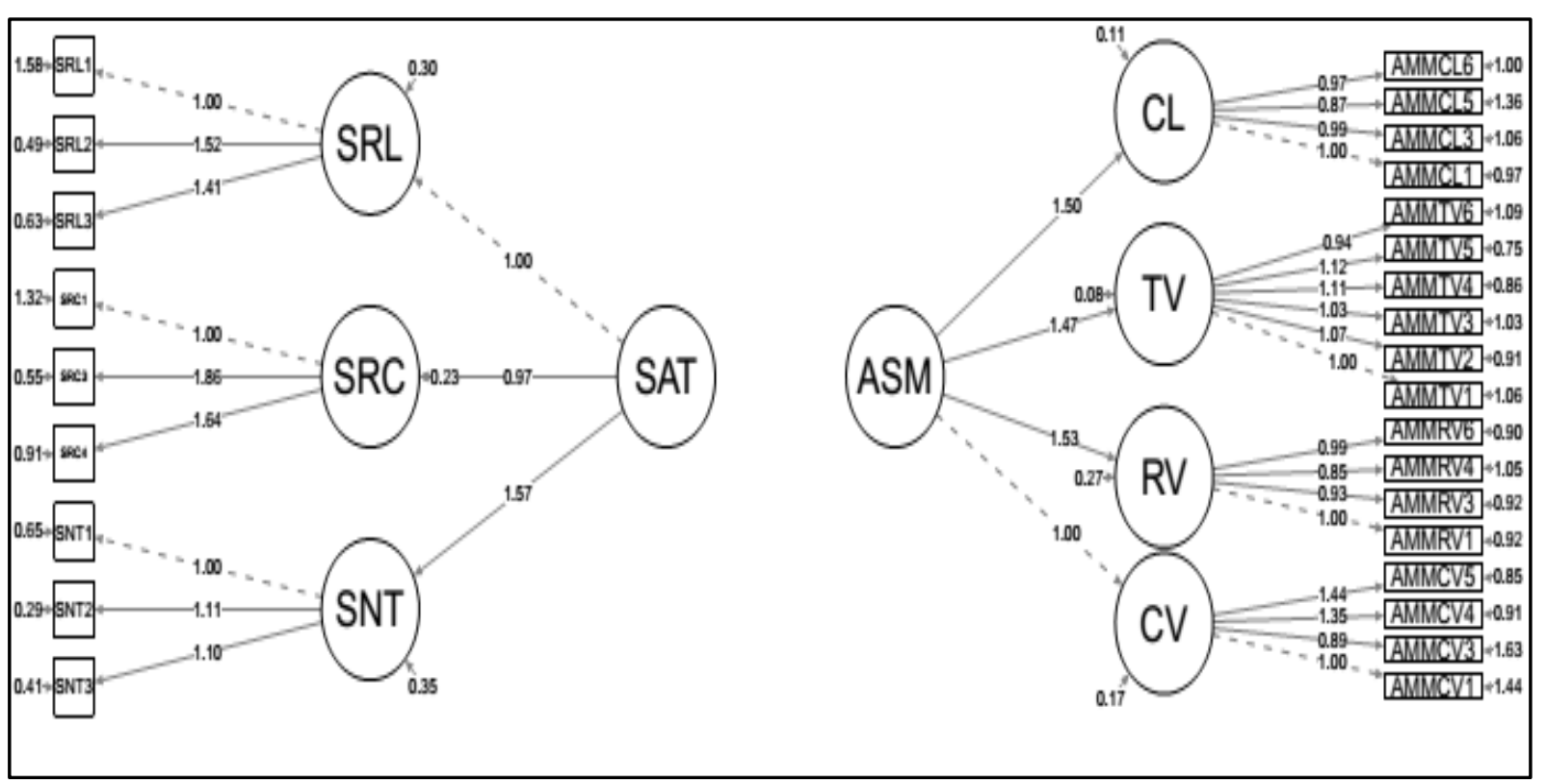

Figura 3. Análise Fatorial Confirmatória em Segunda Ordem para Satisfação no Trabalho e Assédio Moral

Fonte: Elaborada pelos autores. 
Inicialmente, uma análise da matriz de correlação (Spearman) entre os itens revelou algumas correlações acima de 0,70, e isso indica que alguns itens poderiam inflacionar os estimadores da modelagem. Nessa condição, foram excluídos os itens CV2, CV5, RV2 e RV5. O modelo especificado apresentou $\chi^{2}=865,63 \mathrm{com} 131$ g.l., e o resultado foi 6,61 do parâmetro $\chi^{2} / \mathrm{g} .1$., $\mathrm{CFI}=0,91$, TLI $=0,90$, RMSEA $=0,080$ e SRMR $=0,047$, mostrando-se, pois, um ajuste aceitável para ASM, representado na Figura 3. O índice NC ( $\chi 2 / g .1$.) maior do que 5 nos construtos SAT e ASM foi considerado próximo daquele indicado pela literatura, e, ao se incluírem os construtos na modelagem estrutural, os índices NC dos modelos ficaram abaixo de 5 (abaixo de 3 no Modelo 1A na Tabela 1), indicando-se, pois, uma boa modelagem com esses construtos incluídos. Adicionalmente, os outros índices (CFI, TLI e SRMR) estão dentro dos parâmetros de aceitação, e, como a estatística $\chi 2$ tende a piorar com amostras superiores a 300, o ajuste pode ser considerado satisfatório para os dois construtos.

\section{Resultados}

As três escalas foram submetidas à verificação de validade convergente por meio da confiabilidade composta (ou confiabilidade de construto, CC) e variância média extraída (VME), como indicado por Hair, Black, Babin, Anderson e Tatham (2009), com resultados apresentados na Tabela 1. Complementarmente, verificou-se que as cargas fatoriais dos itens nos construtos latentes de $1^{\mathrm{a}}$ ordem, e destes, no construto de $2^{\mathrm{a}}$ ordem, são significativas e superiores a 0,50 (Figuras 2 e 3 ). Já a validade discriminante foi observada a partir da comparação entre a VME do fator e o quadrado das correlações entre os fatores (Hair et al., 2009). O teste aponta validade discriminante para todos os construtos, com exceção das culturas hierárquica e adhocrática, que, como visto na Tabela 1, apresentaram VME de 0,40 e 0,45 , respectivamente. Apesar do valor um pouco mais baixo do que o recomendado pela literatura (> 0,50), foi considerado que os demais indicadores do modelo apresentaram parâmetros dentro do esperado, além do fato de o questionário ter sido aplicado em diferentes organizações de variados setores, o que prejudicou o construto de cultura nos tipos citados.

Tabela 1

\section{Indicadores das Escalas Utilizadas}

\begin{tabular}{lllllll}
\hline & Satisfação & Assédio & Clã & Adhocracia & Mercado & Hierarquia \\
\hline Confiabilidade composta & 0,74 & 0,95 & 0,87 & 0,83 & 0,85 & 0,80 \\
\hline Variância média extraída & 0,48 & 0,84 & 0,58 & 0,45 & 0,53 & 0,40 \\
\hline
\end{tabular}

Nota. Fonte: Elaborada pelos autores.

Por fim, a modelagem de equações estruturais com as relações entre as variáveis foi especificada e estimada, e gerou-se o Modelo 1, que apresentou alguns indicadores insatisfatórios, e, a partir da capacidade de redução da estatística $\chi^{2}>10$, foi incluída no modelo alternativo $1 \mathrm{~A}$ a estimação da covariância entre os itens pertencentes à mesma variável latente de primeira ordem para os três construtos (cultura, assédio e satisfação) com os resultados mostrados na Tabela 2.

Tabela 2

Resultados da Modelagem de Equações Estruturais

\begin{tabular}{lccccccc}
\hline Modelo & $\chi^{\mathbf{2}}$ & GL & $\chi^{\mathbf{2}} /$ GL & CFI & TLI & RMSEA & SRMR \\
\hline Modelo 1 & $3.857,88$ & 1.105 & 3,49 & 0,88 & 0,87 & 0,054 & 0,066 \\
\hline Modelo 1A & $3.045,77$ & 1.078 & 2,82 & 0,91 & 0,90 & 0,046 & 0,059 \\
\hline
\end{tabular}

Nota. Fonte: Elaborada pelos autores. 
O Modelo 1A apresenta parâmetros adequados e pode ter seus estimadores associados ao grau de influência que as variáveis exógenas ou explicativas têm sobre as variáveis endógenas ou explicadas. A Figura 4 apresenta os estimadores com efeitos diretos sobre as variáveis ASM (assédio moral) e SAT (satisfação no trabalho).

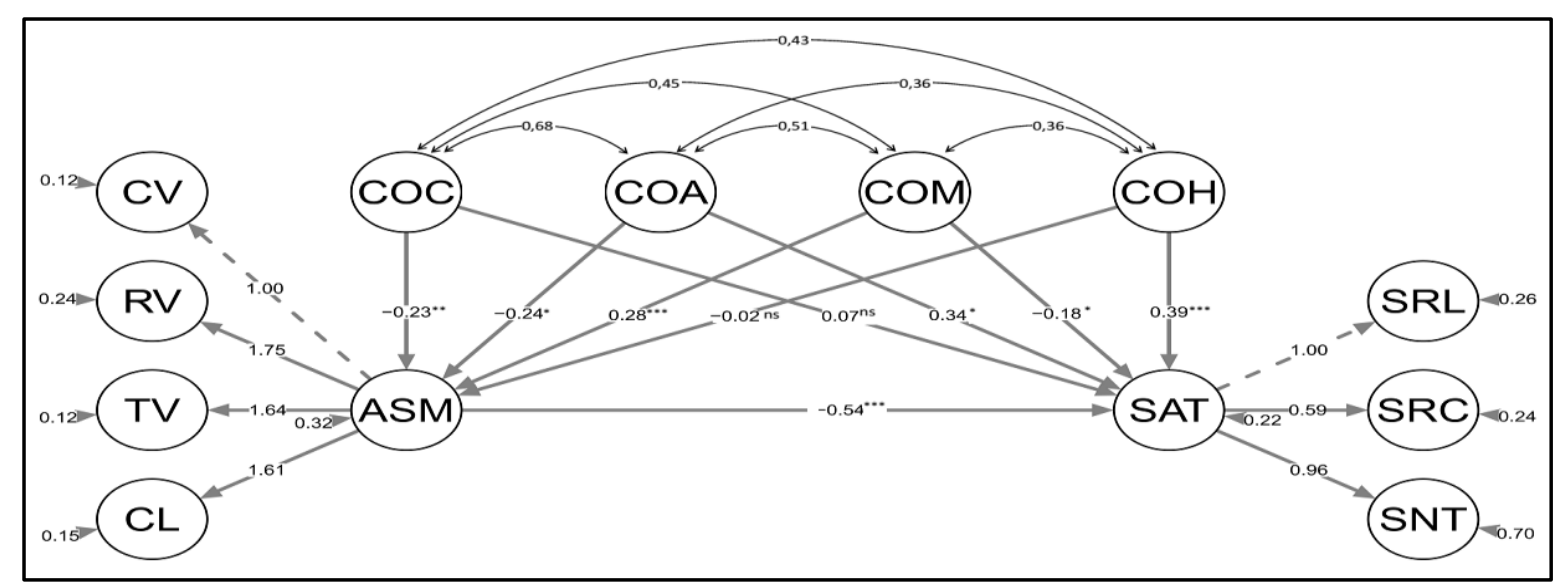

Figura 4. Modelo Estrutural para Cultura Organizacional, Assédio Moral e Satisfação no Trabalho Variáveis manifestas omitidas na representação gráfica. Fonte: Elaborada pelos autores.

Significância dos estimadores: $(*)$ p-valor $<0,05,(* *)$ p-valor $<0,01,(* * *)$ p-valor $<0,001$, (ns) p-valor $>0,05$.

Percebe-se que os elementos da cultura clã (COC) e adhocracia (COA) apresentam uma relação negativa com o assédio moral (ASM), e isso indica aceitação das hipóteses H2a e H2b, enquanto a cultura de mercado (COM) apresenta uma relação positiva (H2c aceita), e a cultura hierárquica não apresentou relação significativa (H2d não aceita). Em relação à influência na satisfação no trabalho (SAT), as culturas adhocracia $(\mathrm{COA})$ e hierárquica $(\mathrm{COH})$ apresentaram uma relação positiva e permitiram aceitação de H1b e não aceitação de H1d, enquanto a cultura de mercado (COM) apresentou relação negativa (aceitou-se H1c), e a cultura clã (COC) não apresentou relação significativa (H1a não aceita). O efeito da mediação do assédio moral (ASM) leva em consideração o estimador que relaciona a cultura ao assédio $(e, f, g$ e $h)$, multiplicado pelo estimador que relaciona o assédio à satisfação $(i)$. Em relação à mediação do assédio na relação entre cultura organizacional e satisfação, os resultados estão apresentados na Tabela 3 .

A análise dos estimadores indica que, para a cultura clã (COC), não parece haver influência direta na satisfação. Porém, ao ser mediada por assédio, existe uma influência positiva e significativa da cultura clã na satisfação no trabalho, o que rejeita a hipótese H4 para essa cultura. Na cultura adhocrática (COA), a influência direta e positiva na satisfação é representada pelo estimador $f(0,343)$. Na mediação do assédio, a influência continua positiva e significativa, porém com a magnitude sensivelmente diminuída $(0,128)$, e aceita-se H4.

Tabela 3

Estimadores de Cultura com Efeito Direto e Mediado pelo Assédio Moral (ASM) na Satisfação

\begin{tabular}{lcccccc}
\hline Variável exógena & \multicolumn{3}{c}{$\begin{array}{c}\text { Efeito direto da cultura na satisfação } \\
\text { (SAT) }\end{array}$} & \multicolumn{3}{c}{$\begin{array}{c}\text { Efeito mediado pelo assédio moral } \\
\text { (ASM) na satisfação (SAT) }\end{array}$} \\
\cline { 2 - 7 } & Est. & Valor & p-valor & Est. & Valor & p-valor \\
\hline Clã - COC & $a$ & 0,075 & 0,305 & $e \times i$ & 0,124 & 0,002 \\
\hline Adhocracia - COA & $b$ & 0,343 & 0,014 & $f \times i$ & 0,128 & 0,038 \\
\hline Mercado - COM & $c$ & $-0,177$ & 0,022 & $g \times i$ & $-0,154$ & 0,000 \\
\hline Hierárquica - COH & $d$ & 0,393 & 0,000 & $h \times i$ & 0,012 & 0,727 \\
\hline Assédio - ASM & $i$ & $-0,542$ & 0,000 & - & - & - \\
\hline
\end{tabular}

Nota. Fonte: Elaborada pelos autores.

RAC, Rio de Janeiro, v. 22, n. 2, art. 5, pp. 249-270, março/abril 2018

Www.anpad.org.br/rac $(\mathrm{cc})$ E 
A cultura de mercado (COM) tem influência negativa na satisfação, e, mediada pelo assédio, essa influência continua negativa com magnitude muito próxima (aceitando-se H4). Por fim, a cultura hierárquica $(\mathrm{COH})$ apresenta estimador positivo e significativo para satisfação. Ao ser considerada a mediação do assédio, essa influência perde significância (e aceita-se H4). Assim, H4 é aceita para os tipos culturais adhocrático $(\mathrm{COA})$, mercado $(\mathrm{COM})$ e hierárquico $(\mathrm{COH})$, sendo rejeitada para o tipo clã (COC). Esses resultados indicam que as situações de assédio podem ter diferentes influências nas diversas culturas organizacionais, conforme discussão a seguir.

\section{Discussão dos Resultados}

Dos dados, emergiu que as culturas clã e adhocrática apresentaram resultados significativo e negativo em relação ao assédio moral, a cultura de mercado também apresentou resultados significativo e positivo, enquanto a cultura hierárquica não apresentou significância estatística. No caso das culturas clã e adhocrática, os resultados mostram uma relação inversa com o assédio moral, e tal fato sugere que a existência de características culturais clã e adhocrática no ambiente organizacional reduz a possibilidade de assédio moral. Essa constatação faz sentido empírico e teórico. Se o assédio é um conjunto de práticas abusivas e ofensivas que buscam destruir psicologicamente o indivíduo (Freitas et al., 2008; Hirigoyen, 2014; Leymann, 1990, 1996), é improvável que esse comportamento seja patrocinado por uma organização cuja cultura se mostre caracterizada pelas culturas clã e adhocrática. A cultura clã possui um conjunto de características que podem funcionar no sentido inverso do favorecimento do assédio moral, já que entre os elementos desse favorecimento destacam-se a visão de integração, a solidariedade entre os membros da organização, a coesão e o compromisso corporativo (Cameron \& Quinn, 2006; Hartnell et al., 2011), o que confirma a hipótese H2a.

Fato semelhante ocorre com a cultura adhocrática, o que justifica o sinal do estimador negativo, quando em relação com o assédio moral. Na adhocracia, o foco na flexibilidade no trabalho dos membros, na criatividade e na inovação, bem como em uma visão idealista de futuro da organização, deve provocar nos membros um sentimento que minimiza os fatores que podem favorecer o aparecimento do assédio moral, reafirmando-se, pois, a hipótese H2b. Por outro lado, a cultura de mercado se mostrou relacionada positivamente com o assédio moral e indica que aumentos da característica dessa cultura no ambiente de trabalho tendem a intensificar o assédio moral nas organizações. Leymann (1990, 1996), C. A. Guimarães et al. (2016) e Suarez (2002) consideram que as transformações ocorridas no mundo, a exemplo da globalização, aumento da competitividade entre as empresas e aumento da pressão por resultados, podem colocar sobre os membros da organização a busca constante por resultados, com a inclusão do incentivo pela competição entre eles. Esse conjunto de características se associa à tipologia de cultura de mercado que favorece a busca por metas, resultados financeiros e competitividade entre os membros da organização (Cameron \& Quinn, 2006; Fernandes et al., 2015; Hartnell et al., 2011). Sendo assim, o resultado encontrado é coerente com a hipótese H2c.

No que se refere à relação entre cultura organizacional e satisfação, os dados parecem espelhar as expectativas dos pesquisadores e demonstram ser a cultura organizacional preditora da satisfação (Andrade, Limana, Estivalete, \& Tanscheit, 2013; Hauff et al., 2015; Peltokorpi \& Froese, 2014; Zhang \& Zheng, 2009). A cultura clã não se mostrou significativa, o que contraria uma expectativa inicial de que, em ambientes nos quais se operam características culturais do tipo clã, há uma tendência de se ampliar o grau de satisfação, conforme hipótese H1a. A explicação provável é que os membros pertencem a organizações mais voltadas para o mercado cuja cultura menos valorizada é a clã. Outra possibilidade pode referir-se às dimensões da satisfação utilizadas nesta pesquisa: oportunidades de promoção, relacionamento com a supervisão e natureza do trabalho. Estas facetas não estão totalmente relacionadas às características da cultura clã, já que estas dimensões podem favorecer mais distanciamento entre os indivíduos do que a proximidade entre eles, como, por exemplo, a oportunidade de promoção que pode induzir à competição. Isso se assemelha ao achado de Santos e Sustelo (2009), que identificou a falta de relação entre cultura de apoio (clã) e satisfação com a natureza do trabalho. 
No caso da cultura adhocrática, o resultado está dentro do esperado e descrito na literatura, uma vez que suas características se assemelham ao que os autores consideram como antecedentes da satisfação: autonomia, flexibilidade, valorização da inovação (Bigliardi et al., 2012; Peltokorpi \& Froese, 2014; Sanchez-Seller et al., 2014; Strese et al., 2016; Tamayo, 2001). Assim, à medida que a cultura adhocrática se assemelha ao que se aproxima do conteúdo da satisfação, o resultado aqui encontrado respalda a relação da cultura adhocrática como preditora da satisfação e reforça a descrição da hipótese H1b. No caso da cultura hierárquica, marcada pela crença de que a eficiência e pontualidade dependem de mecanismos de controle claros, estabilidade e previsibilidade (Cameron \& Quinn, 2006; Denison \& Spreitzer, 1991; Hartnell et al., 2011), a satisfação pode estar associada também ao fato de que os indivíduos em determinados contextos preferem que as regras do jogo estejam claras, uma vez que isso facilita a realização de tais atividades. Além disso, como destacam Sanchez-Sellero et al. (2014), um componente importante da satisfação é a expectativa do indivíduo sobre o seu trabalho (Peltokorpi \& Froese, 2014). E é possível que as expectativas de parte dos indivíduos da amostra estejam sendo atingidas pela forma como as organizações definem o trabalho deles. Entretanto, este resultado contraria a expectativa da hipótese H1d.

Por fim, a cultura de mercado apresentou resultado tanto significativo quanto negativo. $\mathrm{O}$ ambiente organizacional da cultura de mercado é marcado por competição entre os indivíduos, além da pressão por resultados (Cameron \& Quinn, 2006; Denison \& Spreitzer, 1991; Hartnell et al., 2011; Strese et al., 2016). Por conta disso, os indivíduos podem ver esse fenômeno como uma fonte de estresse constante, o que poderá contribuir para os mesmos não se realizarem com o trabalho. E isso se justifica porque a satisfação se compõe de elementos afetivos, aspecto que a competitividade acirrada entre os membros não consegue sustentar (Locke, 1976; Martins \& Santos, 2006; Tamayo, 2001). Estes achados reforçam a perspectiva da hipótese H1c. Outro aspecto importante é o efeito do assédio moral sobre a satisfação. Os resultados confirmam a hipótese $\mathrm{H3}$ de que este fenômeno afeta a satisfação dos trabalhadores. O estimador é negativo e significativo, indicando uma relação inversa entre o assédio moral e satisfação, reforçando os achados de Siqueira (2008) e Andrade, Costa, Estivalete e Lengler (2017).

No que se refere ao efeito mediador do assédio moral na relação entre os tipos de cultura e a satisfação, os dados sugerem que o assédio moral altera a relação existente entre cultura e satisfação. Essa constatação denota o efeito perverso do assédio moral, que, de alguma forma, parece inibir o efeito da cultura sobre o comportamento dos indivíduos, além de afetar-lhes ainda a satisfação no trabalho. Com exceção da cultura clã, que apresentou um resultado inesperado ao ser mediada pelo assédio moral, uma vez que as características dessa cultura tendem a tornar-se ainda menos impactantes na satisfação, as demais culturas e os referidos efeitos sobre a satisfação parecem estar dentro do esperado nesta pesquisa. Entretanto, a hipótese H4 não se confirma, tendo em vista a diferença encontrada na cultura clã. Como já discutido, o efeito do assédio moral sobre a relação entre cultura clã e satisfação, em função das dimensões de satisfação utilizadas, pode ser semelhante ao encontrado por Ertureten, Cemalcilar e Aycan (2013), ao se detectarem aumentos de comprometimento instrumental na presença do assédio moral, devido às características que representam este tipo de comprometimento. Isto é, para este grupo de fatores da satisfação, os indivíduos, na presença do assédio moral, têm ampliado o efeito positivo da cultura clã sobre a satisfação. Como sugestão de investigações futuras em outros contextos, é possível que o assédio moral passe a atuar como fator de coesão entre os indivíduos, provocando mais satisfação.

A cultura hierárquica, que tinha sido positivamente preditora da satisfação, na presença do assédio moral deixa de ser significativa e indica que, no limite, o efeito dela sobre a satisfação não é forte o suficiente para continuar operando em condições de assédio. Quanto à cultura hierárquica, ainda que tenhamos justificado sua relação positiva com a satisfação, é fato que ela contém elementos que podem não estar associados com todas as dimensões da satisfação. Por isso, na presença de mais um elemento inibidor da satisfação, os efeitos positivos diretos sobre a satisfação podem ser diluídos pela presença do assédio moral.

Por sua vez, o efeito mediador do assédio moral entre as culturas adhocrática e mercado e a satisfação apresentou resultados que confirmam a relação tanto entre cultura e satisfação (Andrade $e t$ al., 2013; Zhang \& Zheng, 2009) quanto entre cultura e assédio moral (C. A. Guimarães et al., 2016; 
Lima, Barbosa, Mendes, \& Patta, 2014; M. Rodrigues \& Freitas, 2014; Vasconcelos, 2015). Nesses casos, para a cultura mercado, cuja influência anterior era negativa para a satisfação, e positiva para o assédio, o sinal após a mediação da cultura na satisfação continuou negativo, demonstrando-se a relação próxima entre assédio moral e cultura de mercado. Isso confirma que, em organizações cuja cultura é caracterizada como de mercado, a presença do assédio moral tende a reduzir o nível de satisfação dos membros da organização.

No caso da cultura adhocrática, cujo estimador que prediz a satisfação é positivo, a sua magnitude, quando mediada pelo assédio moral, sofre uma importante redução. Isso indica o efeito danoso do assédio moral, inclusive sobre o contexto sociocultural presente na organização. Assim, sugere-se que, apesar de a cultura organizacional indicar situações de estabilidade, por ser uma construção social, seus elementos parecem sofrer influência significativa quando situações de assédio se manifestam na organização, já que se reduzem os efeitos sobre a satisfação. Retomando as afirmações sobre os efeitos do assédio moral sobre o indivíduo e a organização (C. A. Guimarães et al., 2016; Hirigoyen, 2014; Leymann, 1990, 1996; Suarez, 2002), esses achados permitem se inferir que o efeito do assédio moral sobre o comportamento dos indivíduos e sobre sua satisfação parece mais intenso do que a cultura organizacional é capaz de inibir.

Dado que a cultura é vista como valores, crenças e expectativas normativas sociais que indicam os comportamentos aceitáveis (Hartnell et al., 2011), como um sistema de símbolos e significados onde as interações tomam lugar (Alvesson, 2007) ou como uma teia de significados tecida pelos membros de uma comunidade (Geertz, 1989), ela poderia inibir práticas que sejam contrárias a seu conjunto de valores, como seria o caso da cultura clã. Entretanto, pelos resultados, lança-se uma reflexão que, mesmo em um perfil de cultura não favorável ao assédio moral, na presença deste, a cultura não consegue sustentar os próprios efeitos positivos sobre a satisfação.

\section{Conclusão}

O objetivo deste trabalho foi avaliar a relação entre o assédio moral, a cultura organizacional e a satisfação no trabalho. Partindo de uma abordagem quantitativa, foi possível identificar as relações estabelecidas entre esses conceitos. As culturas clã e adhocrática se revelaram numa relação inversa entre seus componentes e o assédio moral, com a indicação de que culturas adhocráticas e clã tendem a reduzir a presença do assédio moral. Por outro lado, a cultura de mercado se revelou positivamente associada ao assédio moral e indica que a presença daquela favorece o aparecimento deste.

$\mathrm{Na}$ relação da cultura com a satisfação, as culturas adhocrática e hierárquica se mostraram positivamente associadas com a satisfação, enquanto a cultura de mercado se revelou inversamente relacionada com a satisfação. A cultura clã não apresentou significância estatística. Por outro lado, o assédio moral confirmou a expectativa na literatura, uma vez que apresenta uma influência negativa na satisfação no trabalho. E, por fim, destaca-se o efeito mediador do assédio na influência da cultura sobre a satisfação, dado que se revelou importante neste trabalho.

Os achados vinculados ao efeito mediador do assédio moral reforçam a preocupação da existência do assédio moral no contexto das organizações. Isso porque, mesmo em um contexto no qual as culturas sejam inibidoras de práticas de assédio moral, a presença deste pode reduzir o efeito positivo ou o negativo da cultura sobre a satisfação. Isso sinaliza a necessidade de se ampliarem as discussões sobre este fenômeno, já que se poderá dizer que ele produz consequências tão fortes, a ponto de ser capaz de influir no efeito da cultura organizacional no ambiente de trabalho, o que parece ser uma contribuição deste trabalho.

Outra colaboração deste estudo é a possibilidade de se reforçarem os argumentos acerca dos efeitos dos elementos do contexto organizacional sobre o assédio moral. Parte importante da literatura tem demonstrado de forma qualitativa ou sugerido que esses elementos, incluindo-se a cultura 
organizacional, podem favorecer ou não o surgimento do assédio moral. Nesta pesquisa, fica evidente que a cultura organizacional apresenta um papel relevante no aparecimento ou manutenção do assédio moral no contexto pesquisado.

E, por fim, uma reflexão que ainda pode ser feita é o reforço que este trabalho traz quando se discutem os efeitos do assédio moral sobre a satisfação. Por se considerar que esta é preditora de outros comportamentos dos indivíduos na organização, que incluem comprometimento e efetividade, e, ainda, que o assédio moral tem influência direta sobre a satisfação, sugere-se que sejam ampliadas as formas de controle desse fenômeno nas organizações, posto que baixa produtividade, baixa qualidade e outros males causados pelo assédio moral podem levar pessoas e organizações a prejuízos significativos.

Entre as limitações deste estudo, destaca-se a amostra composta por indivíduos de empresas diferentes, o que torna difícil caracterizar a cultura de uma organização. Além disso, por se tratar de pesquisa com vários conceitos, os instrumentos de coleta de dados de satisfação e assédio moral foram utilizados parcialmente, em função do tamanho que o instrumento poderia ter, caso fossem usados na totalidade. E a amostra foi limitada a apenas duas cidades e a apenas um estado da federação brasileira.

Novos estudos podem analisar o caso de a cultura clã não gerar satisfação, ou essa mesma cultura, na presença do mediador assédio, transformar-se em preditora da satisfação. Além disso, estudos que possam analisar os efeitos da cultura nas diversas dimensões de assédio moral e da satisfação também podem ser úteis, para permitirem que se compreenda como tipologias de culturas podem atuar diferentemente em cada uma das dimensões desses conceitos. Também se sugere ampliar a amostra para públicos maiores e diferentes, além de se realizarem estudos em organizações específicas para se preservar a homogeneidade da amostra e se melhorar a compreensão do fenômeno aqui estudado.

\section{Referências}

Alvesson, M. (2007). Understanding organizational culture. London: SAGE Publications.

Andrade, T., Costa, V. F, Estivalete, V. de F. B., \& Lengler, L. (2017). Comportamento de cidadania organizacional: Um olhar à luz dos valores e da satisfação no trabalho. Revista Brasileira de Gestão de Negócios, 19(64), 236-262. http://dx.doi.org/10.7819/rbgn.v19i64.2899

Andrade, T., Limana, S., Estivalete, V. de F. B., \& Tanscheit, F. (2013). Cultura organizacional e satisfação no trabalho sob a percepção dos colaboradores de uma instituição bancária após o processo de fusão. Revista Administração e Diálogo, $15(2), \quad 52-78$. http://dx.doi.org/10.20946/rad.v15i2.12705

Bigliardi, B., Dormio, A. I., Galati, F., \& Schiuma, G. (2012). The impact of organizational culture on the job satisfaction of knowledge workers. VINE, 42(1), 36-51. http://dx.doi.org/10.1108/03055721211207752

Braga, G. G. A., Ferraz, S. F. S., \& Lima, T. C. B. (2014). Cultura organizacional em empresas industriais: Um estudo nas maiores empresas de Maracanaú/CE. Revista Eletrônica de Ciência Administrativa, 13(2), 250-266. http://dx.doi.org/10.1108/03055721211207752

Cameron, K. S., \& Quinn, R. E. (2006). Diagnosing and changing organizational culture - Based on the competing values framework. San Francisco, CA: Jossey-Bass

Campos, M. I., \& Rueda, F. J. M. (2016). Assédio moral: Evidências de validade de escala e relações com qualidade de vida no trabalho. Avaliação Psicológica, 15(1), 21-30

Denison, D. R., \& Spreitzer, G. M. (1991). Organizational culture and organizational development: A competing values approach. Research in Organizational Change and Development, 5, 1-21. 
Divincova, A., \& Sivakova, B. (2014). Mobbing at workplace and its impact on employee performance. Human Resources Management \& Ergonomics, 8(2), 20-34.

Ertureten, A., Cemalcilar, Z., \& Aycan, Z. (2013). The relationship of downward mobbing with leadership style and organizational attitudes. Journal of Business Ethics, 116(1), 205-216. http://dx.doi.org/10.1007/s10551-012-1468-2

Fernandes, R. F., Lemos, D. C., Hoffmann, M. G., \& Feuerchutte, S. G. (2015). O estado da arte na articulação entre os temas cultura organizacional e inovação. Revista Pensamento Contemporâneo em Administração, 9(4), 54-68. http://dx.doi.org/10.12712/rpca.v9i4.504

Freitas, M. E. (2001). Assédio moral e assédio sexual: Faces do poder perversos nas organizações. Revista de administração de Empresas, 41(2), 8-19. http://dx.doi.org/10.1590/S003475902001000200002

Freitas, M. E., Heloani, J. R., \& Barreto, M. M. S. (2008). Assédio moral no trabalho. São Paulo: Cengage Learning.

$\mathrm{Fu}, \mathrm{W}$. (2014). The impact of emotional intelligence, organizational commitment, and job satisfaction on ethical behavior of Chinese employees. Journal of Business Ethichs, 122(1), 137-144. http://dx.doi.org/10.1007/s10551-013-1763-6

Geertz, C. (1989). A interpretação das culturas. Rio de Janeiro: Guanabara Koogan.

Guimarães, C. A., Cançado, V., \& Lima, R. J. C. (2016). Workplace moral harassment and its consequences: A case study in a federal higher education institution. Revista de Administração, 51(2), 151-164. http://dx.doi.org/10.5700/rausp1231

Guimarães, L. A. M., \& Rimoli, A. O. (2006). Mobbing (assédio psicológico) no trabalho: Uma síndrome psicossocial multidimensional. Psicologia Teoria e Pesquisa, 22(2), 183-192. http://dx.doi.org/10.1590/S0102-37722006000200008

Hair, J. F., Black, W. C., Babin, B. J., Anderson, R. E., \& Tatham, R. L. (2009). Análise multivariada de dados. Porto Alegre: Bookman.

Hartnell, C. A., Ou, A. Y., \& Kinicki, A. (2011). Organizacional culture and organizational effectiveness: A meta-analytic investigation of the competing values framework's theorical suppositions. Journal of Applied Psychology, 96(4), 677-694. http://dx.doi.org/10.1037/a0021987

Hauff, S., Richter, N. F., \& Tressin, T. (2015). Situational job characteristics and job satisfaction: The moderating role of national culture. International Business Review, 24(4), 710-723. http://dx.doi.org/10.1016/j.ibusrev.2015.01.003

Hennekam, S., \& Bennett, D. (2017). Sexual harassment in the creative industries: Tolerance, culture and the need for change. Gender, Eork \& Organization, 24(4), 417-434. http://dx.doi.org/10.1111/gwao.12176.

Hirigoyen, M. F. (2014). Assédio moral: A violência perversa no cotidiano (15a ed.). Rio de Janeiro: Bertrand Brasil.

Hooper, D., Coughlan, J., \& Mullen, M. R. (2008). Structural equation modelling: Guidelines for determining model fit. Eletronic Journal of Bussiness Research Methods, 6(1), 53-60. Retrieved from https://www.researchgate.net/publication/254742561_Structural_Equation_Modeling_Guideline s_for_Determining_Model_Fit 
Leymann, H. (1990). Mobbing and psychological terror at workplaces. Violence and Victims, 5(2), 119126.

Leymann, H. (1996). The content and development of mobbing at work. European Journal of Work and Organisational Psychology, 5(2), 165-184. http://dx.doi.org/10.1080/13594329608414853

Lima, C. Q. B., Barbosa, C. M. G., Mendes, R. W. B., \& Patta, C. A. (2014). Assédio moral e violência no trabalho: Caracterização em perícia judicial. Relato de experiência no setor bancário. Revista Brasileira de Saúde Ocupacional, 39(129), 101-110. http://dx.doi.org/10.1590/03037657000050313

Locke, E. A. (1976). The nature and causes of job satisfaction. In M. D. Dunnette (Ed.), Handbook of industrial and organizational psychology (pp. 1297-1349). Chicago: Rand McNally.

Martins, M. C. F., \& Santos, G. E. (2006). Adaptação e validação de construto da escala de satisfação no trabalho. Psico-USF, 11(2), 195-205. http://dx.doi.org/10.1590/S1413-82712006000200008

Marôco, J. (2010). Análise de equações estruturais. Pero Pinheiro: Report Number.

Nunes, T. S., \& Tolfo, S. R. (2013). A dinâmica e os fatores organizacionais propiciadores à ocorrência do assédio moral no trabalho. Revista de Gestão e Secretariado, 4(2), 90-113. http://dx.doi.org/10.7769/gesec.v4i2.161

Oliveira, L. B., \& Costa, F. P. C. (2016). Motivação, satisfação e comprometimento: Um estudo sobre o trabalho voluntário em megaeventos esportivos. Revista Economia \& Gestão, 16(42), 89-115. http://dx.doi.org/10.5752/P.1984-6606.2016v16n42p89

Olsson, U. H., Foss, T., Troye, S. V., \& Howell, R. D. (2000). The performance of ML, GLS and WLS estimation in structural equation modelling under conditions of misspecification and

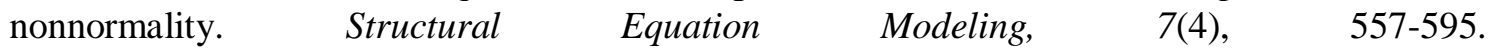
http://dx.doi.org/10.1207/S15328007SEM0704_3

Parzefall, M. R., \& Salin, D. M. (2010). Perceptions of and reactions to workplace bullying: A social exchange perspective. Human Relations, 63(6) 761-780. http://dx.doi.org/10.1177/0018726709345043

Peltokorpi, V., \& Froese, F. (2014). Expatriate personality and cultural fit: The moderating role of host country context on job satisfaction. International Business Review, 23(1), 293-302. http://dx.doi.org/10.1016/j.ibusrev.2013.05.004

Rodrigues, A. L., Barrichello, A., \& Morin, E. (2016). Os sentidos do trabalho para profissionais de enfermagem: Um estudo multimétodos. Revista de Administração de Empresas, 56(2), 192-208. https://dx.doi.org/10.1590/S0034-759020160206

Rodrigues, M., \& Freitas, M. E. (2014). Assédio moral nas instituições de ensino superior: Um estudo sobre as condições organizacionais que favorecem sua ocorrência. Cadernos EBAPE.BR, 12(2), 284-301. https://dx.doi.org/10.1590/1679-39518275

Roman, S., Sefano, S. R., Andrade, S. M., \& Zampier, M. A. (2012). Análise do comprometimento organizacional e sua natureza em relação aos funcionários públicos municipais. Gestão \& Regionalidade, 28(84), 5-19. https://dx.doi.org/10.13037/gr.vol28n84.1280

Rosseel, Y. (2012). Lavaan: A R package for equation structural modeling. Journal of Statistical Software, 48(2), 1-36. https://dx.doi.org/10.18637/jss.v048.i02

Rueda, F. J. M., Baptista, M. N., \& Cardoso, H. F. (2015). Construção e estudos psicométricos iniciais da Escala Laboral de Assédio Moral (ELAM). Avaliação Psicológica, 14(1), 33-40. 
Salin, D., Tenhiälä, A., Roberge, M. E., \& Berdahl, J. L. (2014). 'I wish I had . . ’’ Target reflections on responses to workplace mistreatment. Human Relations, 67(10), 1189-1211. https://dx.doi.org/10.1177/0018726713516375

Sanchez-Sellero, M. C., Sánchez-Sellero, P., Cruz-González, M. M., \& Sánchez- Sellero, F. J. R. (2014). Características organizacionales de la satisfacción laboral en España. Revista de Administração de Empresas, 54(5), 537-547. http://dx.doi.org/10.1590/S0034-759020140507

Santos, J. V., \& Sustelo, M. (2009). Cultura organizacional e satisfação profissional: Estudo desenvolvido num hospital privado. Psico, 40(4), 467-472.

Schein, E. H. (2004). Cultura organizacional e liderança. São Paulo: Atlas.

Siqueira, M. M. M. (2008). Satisfação no trabalho. In M.M.M Siqueira (Org.), Medidas do comportamento organizacional: Ferramentas de diagnóstico e de gestão (pp. 265-274). Porto Alegre: Artmed.

Spector, P. E (1985). Measurement of human service staff satisfaction: Development of the job satisfaction survey. American Journal of Community Psychology, 13(6), 693-713. https://doi.org/10.1007/BF00929796

Spector, P. E. (2006). Psicologia nas organizações (2a ed.). São Paulo: Saraiva.

Strese, S., Adams, D. R., Flatten, T. C., \& Brettel, M. (2016). Coporative culture and absorptive: The moderating role of national culture dimensions on innovation management. International Business Review, 25(5), 1149-1168. http://dx.doi.org/10.1016/j.ibusrev.2016.02.002

Suarez, O. A. (2002). La violência psicológica em el lugar de trabajo em el marco de la unión europea. Lan Har Remark, (7), 279-296.

Tamayo, A. (2001). Prioridades axiológicas, atividade física e estresse ocupacional. Revista de Administração Contemporânea, 5(3),127-147. http://dx.doi.org/10.1590/S141565552001000300007

Terzioglu, F., Tele, S., \& Uslu Sahan, F. (2016). Factors affecting performance and productivity of nurses: Professional attitude, organisational justice, organizational culture and mobbing. Journal of Nursing Management, 24(6), 735-744. http://dx.doi.org/10.1111/jonm.12377

Tett, R. P., \& Meyer, J. P. (1993). Job satisfaction, organizational commitment, turnover intention, and turnover: Path analysis based on meta-analytic finds. Personnel Psychology, 46(2), 259-293. http://dx.doi.org/10.1111/j.1744-6570.1993.tb00874.x

Vasconcelos, Y. L. (2015). Assédio moral nos ambientes corporativos. Cadernos EBAPE.BR, 13(4), 821-851. http://dx.doi.org/10.1590/1679-395141446

Vieira, V. A. (2009). Moderação, mediação, moderadora-mediadora e efeitos indiretos em modelagem de equações estruturais: Uma aplicação no modelo de desconfirmação de expectativas. Revista de Administração, 44(1), 17-33.

Warr, P. (2007). Work, happiness, and unhappiness. Mahwah, NJ: Lawrence Erlbaum.

Welter, G. M.-R., \& Capitão, C. G. (2007). Medidas ipsativas na avaliação psicológica. Avaliação Psicológica, 6(2), 157-165.

Zhang, J., \& Zheng, W. (2009). How does satisfaction translate into performance? An examination of commitment and cultural values. Human Resource Development Quarterly, 20(3), 331-351. http://dx.doi.org/10.1002/hrdq.20022 


\section{Dados dos Autores}

\section{Lindomar Pinto da Silva}

Rua Dr. José Peroba, 251, 41770-235, Salvador, BA, Brasil. E-mail: lindomar.silva@ pro.unifacs.br; lindomarps@ hotmail.com

Miguel Angel Rivera Castro

Rua Dr. José Peroba, 251, 41770-235, Salvador, BA, Brasil. E-mail: miguel.castro@ pro.unifacs.br. https://orcid.org/00000003-0811-2798

Marcos Gilberto Dos-Santos

Reitor Miguel Calmon, s/n, 40110-060, Salvador, BA, Brasil. E-mail: marcosgilberto74@ gmail.com 